\title{
Demystifying the Common Core in Kindergarten Writing
}

\author{
Susan W. Cress ${ }^{1} \&$ Daniel T. Holm ${ }^{1}$ \\ ${ }^{1}$ School of Education, Indiana University South Bend, IN, USA \\ Correspondence: Susan W. Cress, School of Education, Indiana University South Bend, IN, USA. E-mail: \\ scress@iusb.edu
}

Received: May 3, 2017

Accepted: June 1, 2017

Online Published: June 6, 2017

doi:10.5539/jel.v6n4p92

URL: http://doi.org/10.5539/jel.v6n4p92

\begin{abstract}
Having a set of standards, whether they are common core or state standards, appropriate for kindergarten children is a concern raised by many early childhood educators and parents. Given that at this point and time standards are recognized by many other stakeholders as a way of ensuring children are ready for the future, it is time to further investigate ways to infuse standards into the curriculum in an appropriate way. The developmental appropriateness, and the planning, implementation, and assessment techniques of the curriculum are key to meeting the standards. The article focuses on writing as one example of providing an environment where children can work at their own developmental level. Teachers must be knowledgeable about development, appropriate activities, and the fundamentals of literacy. Samples of kindergarten writing are used to illustrate and explore the possibilities of fostering an appropriate writing curriculum.
\end{abstract}

Keywords: kindergarten, writing, standards, curriculum

\section{Introduction}

Kindergarten teachers struggle with implementing the common core standards. The refrain, spoken with nostalgia, is often; "kindergarten is not what it used to be". A recent popular press article from the New York Post titled, Playtime's over kindergartners standards stressing kids out (Edelman, 2013) summarizes the concerns of many early childhood educators and families. While these unsettling remarks resonate with many teachers, the question remains, what can we do to continue to support kindergarten children in a way that is responsive to the developmental needs of young learners? The curriculum focus might have changed, but these children are still mostly 5 and 6 years old. It is ethically responsible to maintain focus on how to integrate the common core in a way where teachers can describe kindergarten as "better than ever" in providing a content rich curriculum which takes into account development, as well as the rich interests and capabilities of young children.

The national common core standards are meant to increase rigor in the system, provide a foundation for curriculum, and a way of assuring that children will be ready for college. In fact, the authors of the core standards, the National Governor's Association Center for Best Practices and the Council of Chief State School Officers states, "we can ensure that students make progress each year and graduate from school prepared to succeed in college and in a modern workforce" (The Standards, para. 3). While this would seem to be a panacea for the ever-present curriculum woes in the country, early childhood educators rightfully are concerned that this is another case of the push down curriculum threatening the developmental needs of our youngest citizens. However, teachers of young children should view the common core as doable and approachable in the context of best practice. Teachers might well ask, "How can I implement the common core without compromising developmental concerns?"

In order to accomplish such a curriculum mindset teachers will need to focus on providing excellent environments, which foster the child's development, stimulate intellectual curiosity and problem solving, and allow children the opportunity to grow socially and emotionally. Perhaps early childhood educators need to look at the standards as an opportunity to incorporate academics into the curriculum in a new way, by resisting the urge to systematically teach the isolated skills embedded in the standards. Instead, by focusing on experiences that are developmentally appropriate and best practice teachers can ensure they are meeting the common core standards within the context of developmentally appropriateness.

After a brief introduction to the main tenets of the common core and early childhood, the primary purpose of the article is to focus on using the kindergarten common core literacy standards for writing, as an avenue for 
addressing the concerns of kindergarten teachers. In doing so several areas are explored; the pedagogical and developmental knowledge necessary for teachers; environmental considerations; when and where the focus on the standards can best be found, assessment opportunities, and how to differentiate instruction.

\section{The Common Core and Early Childhood}

A policy statement from The National Association for the Education of Young Children (NAEYC, 2012) provides four conditions for using the Common Core in early childhood education. The first condition, "Early Learning standards should emphasize significant developmentally appropriate content and outcomes" (p. 5), strongly suggests that the standards are focused only on literacy and mathematics, which might well not be developmentally appropriate, without consideration of other areas of development. Certainly NAEYC's position is a concern echoed by other experts in the field (Alliance for Childhood, 2010; Snow, 2012).

The second NAEYC condition is that the standards should be thoughtfully planned, with research and practice, and in collaboration with members of the early childhood community $(2012, \mathrm{p}$. 6). The condition is somewhat the antithesis of what actually occurred. The approach was to start with grade 12 and move back to kindergarten, which has resulted in a push down curriculum. The early childhood field should not allow for alignment to flow only downward but should advocate for the "push up" of early childhood standards to inform ongoing development of K-12 standards, including those in areas not part of the Common Core (NAEYC, 2012, p. 6).

The third NAEYC condition (2012) states that the implementation of the standards as well as the methodology for planning and instruction should be the focus. Teachers need to know and use their understanding of development and appropriate methodology in planning how to meet the standards and how to assess them (NAEYC, 2012; Snow, 2012). Strickland (2012) further substantiates this condition in an article on the Common Core standards when she points out the standards do not tell teachers how they should teach, "Together, standards and curriculum provide a process that includes a shared vision of expectations with multiple pathways for attaining them" (p. 25).

The fourth NAEYC condition addresses the requirements of "a foundation of support for early childhood programs, professionals, and families" (2012, pp. 7-8) for without such support implementation will not be possible. It also addresses the need for professional development and support for teachers in identifying appropriate methods for implementing the Common Core in the curriculum. As a lens for approaching the common core the area of writing is considered as an area to begin to look at appropriate curriculum to foster the common core. Table 1 summarizes the specific writing indicators from the common core, what teachers need to know, environmental considerations, assessment opportunities, and the possibilities for differentiated instruction.

\section{What Teachers Need to Know: Pedagogical and Developmental Knowledge of Writing}

In fully understanding any curriculum content there is a body of knowledge that is essential to the teaching of the area. Teachers must understand the specific factors involved in scaffolding the material and presenting new concepts and ideas to the child and to the group. In the content of early writing it is essential that teachers understand the stages of drawing and writing development, scaffolding techniques to help children develop as writers, differentiated instruction strategies to ensure all children learn, how to ask high level questions, the benefits of choice, ways to provide interesting projects to create avenues for research and exploration, and how to model good practice.

\section{Stages of Writing Development}

In one of the classic studies of early writing development Sulzby and Teale (1985) described the stages of writing development. The first stage is "writing via drawing". In this stage the child draws a picture to symbolize the intentions of communication. The child might present a drawing of a stick figure and announce, "I wrote about Grandpa". The second stage "writing via scribbling" is characterized by a wavy line, or a series of lines that symbolizes an attempt to communicate. The child might even ask, "What does this say?" showing both the knowledge that writing is communication and the naiveté in understanding conventional alphabetic awareness or sound symbol relationship. The third stage, is "Writing via Making Letter like Forms". At first glance it would seem these are letters, but upon examination only resemble conventional writing. The fourth stage is "Writing via Reproducing well-Learned units or Letter Strings". In this stage actual strings of letters are produced, mostly without regard for sound symbol relationships, yet appear to be left to right, although in actuality could have been written in any direction. Typically, parts of the child's entire name, or other well-known string of letters, might be seen within the written product. The fifth stage of writing, "Writing via Invented Spelling" is characterized by developmental symbolization of a series of phonetically spelled words that represent the real and developmental sounds the child produces. Wide variation in this stage might include one consonant for a 
word, several consonants, or representation of words in a sentence or story that ranges from developmental to correct spelling throughout the writing piece. "Conventional Writing" is the last stage presented which as the name conveys is writing which has the attributes of adult writing in terms of spelling and communication.

The environment, strategies, and intentional scaffolding of instruction are key to a writing curriculum in kindergarten. The well-designed literacy environment includes many examples of print, centers which reinforce and motivate children to write, a supportive social construct which considers peer and adult interaction during and about the writing process, a teacher who intentionally asks critical questions about literacy, and knowledge of technology in tune, and appropriate for, the interests of many young children (Roskos \& Neuman, 2011).

Numerous strategies are available to foster writing development. While some practices involve the teacher modeling writing, or interacting with the child before, during, and after writing, process writing done by the child on topics of interest are critical to writing development.

Common strategies such as modeling writing during small and large group time are long time practices. The Language Experience Approach (LEA) is important to the kindergarten classroom. Morrow (2012) explains that LEA "helps children associate oral language with written language, teaching them that what is said can be written down and read" (p. 152). Providing experiences, having rich language discussions, taking dictation, and rereading the dictation with the child or children provide a model of conventional writing. In group situations this can be a map of ideas, a list of words, a story, a thank you note, recounting any experience. Individually children draw and dictate to an adult about many ideas and thoughts.

Literacy activities concerning other common practices include writing within the center areas are well documented in the literature (Cress, 2004; Epstein, 2007). This includes such activities as making grocery lists in a house corner, writing about a favorite book in the library center, making tally marks on how many cubes are used for a problem posed in a math center, etc. At the block center drawing and writing directions to get around the construction, menus in the restaurant developed during play. Any project considers the use of writing and drawing by children to document their observations and to make meaning of the world.

Interactive journal writing is also a way to encourage writing. If children are provided with open ended opportunities to write on a topic of choice, they will often spend as much as 45 minutes detailing and describing their pictures and narrative. Especially if children are encouraged to write about a topic of interest to them writing becomes an integral part of the day. It provides the child with a way of making sense about writing stories. Through the interactions teachers can pose questions to sustain the story and motivate the child to continue writing. Other scaffolding techniques might happen through interactive journal writing (Cress, 1998) where children expand on a story or idea through questions the teacher poses as the story develops over time.

Knowing the different phases or stages of writing, and the child's wavering back and forth through such stages allows the teacher to scaffold instruction. Scaffolding considerations are dependent on the knowledge of writing development. With this knowledge the teacher can provide the next step. In the child's writing by focusing on what the child knows. For example, a teacher might say to a child just starting to use an occasional phonetically spelled word, "remember when we were writing about our fall walk in the leaves, we stretched out some of the words to hear the sounds to write? That might be helpful as you write today". Of course writing development is not in isolation from other skills of reading so for example, suggestions concerning concepts of print are also important, "Leave a space between your words and it will be easier to read back".

Assessment opportunities from writing can easily be obtained by creating a work sample which matches the standard, is dated, and represents a child's accomplishments in that particular area. Observations, retelling, and reading back written work are also useful when well-documented over time. Time honored assessments such as anecdotal notes, checklists, and collaboration with families, can be used to assess the standards (Cress, 2004).

\section{Samples of Kindergarten Writing}

Given "what the teacher needs to know" and selected writing standards, Text Types and Purposes, samples of kindergarten writing are presented to clarify kindergarten writing as evidence of meeting the common core standards.

K.W.1 Use a combination of drawing, dictating, and writing to compose opinion pieces in which they tell a reader the topic or the name of the book they are writing about and state an opinion or preference about the topic or book.

After hearing the teacher read the book "Parts" (Arnold, 1997) one child wrote, "I do not like no parts of the book. Why don't you like the book? I don't like it because it's ugly" (Figure 1). Clearly we can see that the child 
has an opinion about the book; in fact a certain amount of passion is indicated by the response. Not only is there evidence of the child's opinion of the book, but the sample provides information about the writing development of the child. The majority of the words contain conventional spelling. The words that are at the developmental spelling level, "prts" for parts, "ov" for of "wi" for "why dot" for don't "bekes" for because and "ugle" for ugly are all phonetically spelled. The child also uses a period and question mark correctly as well as writing left to write and spacing between the words, giving evidence concepts of print are in place. So, not only is this a work sample which can be used as evidence of meeting the standard, but some of the conventions of print and grammar are also appropriate for kindergarten. Providing models of writing and conventions will scaffold the child's writing as the year progresses. Reading books of interest to children and providing time or centers to discuss books and react in writing are consistent with positive experiences in writing.

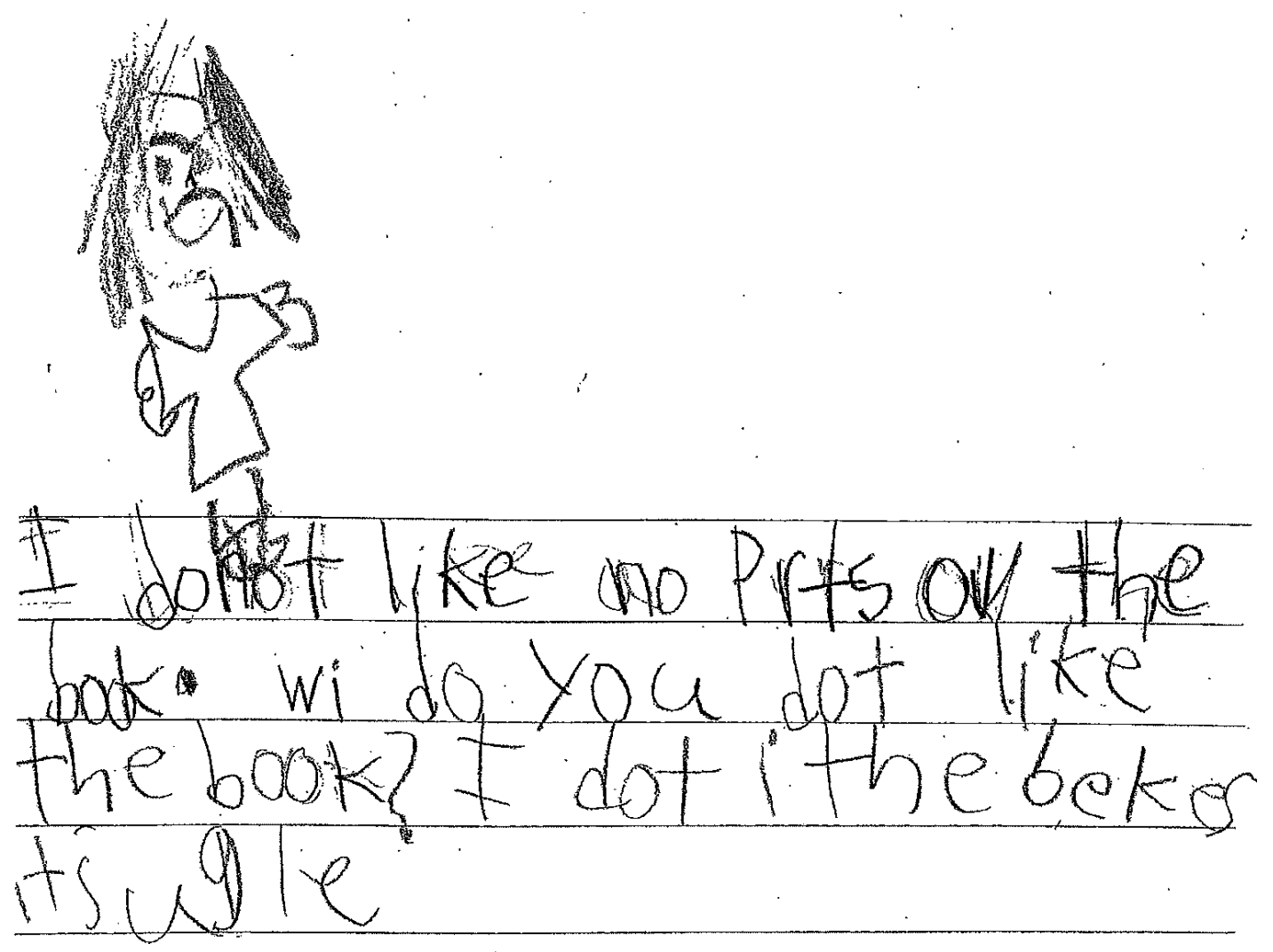

Figure 1. Parts

K.W.2 Use a combination of drawing, dictating, and writing to compose informative/explanatory texts in which they name what they are writing about and supply some information about the topic.

The giraffe (Figure 2) in the drawing represents the very beginning step of meeting the standard, yet certainly within the developmental stages of writing in kindergarten. The oral language surrounding the event, "this is a giraffe at the zoo" begins to tell the story. The GF provides the teacher with evidence that beginning and ending sounds are written, that the child knows the print and the drawing should match. Other opportunities in the classroom, computer access, books, magazines, could be presented to further engage the child in studying about giraffes if the interest persists. The teacher might pose a question to scaffold interest, "What do you wonder about giraffes?" Oral conversations also might be dictated to the teacher to transcribe. 


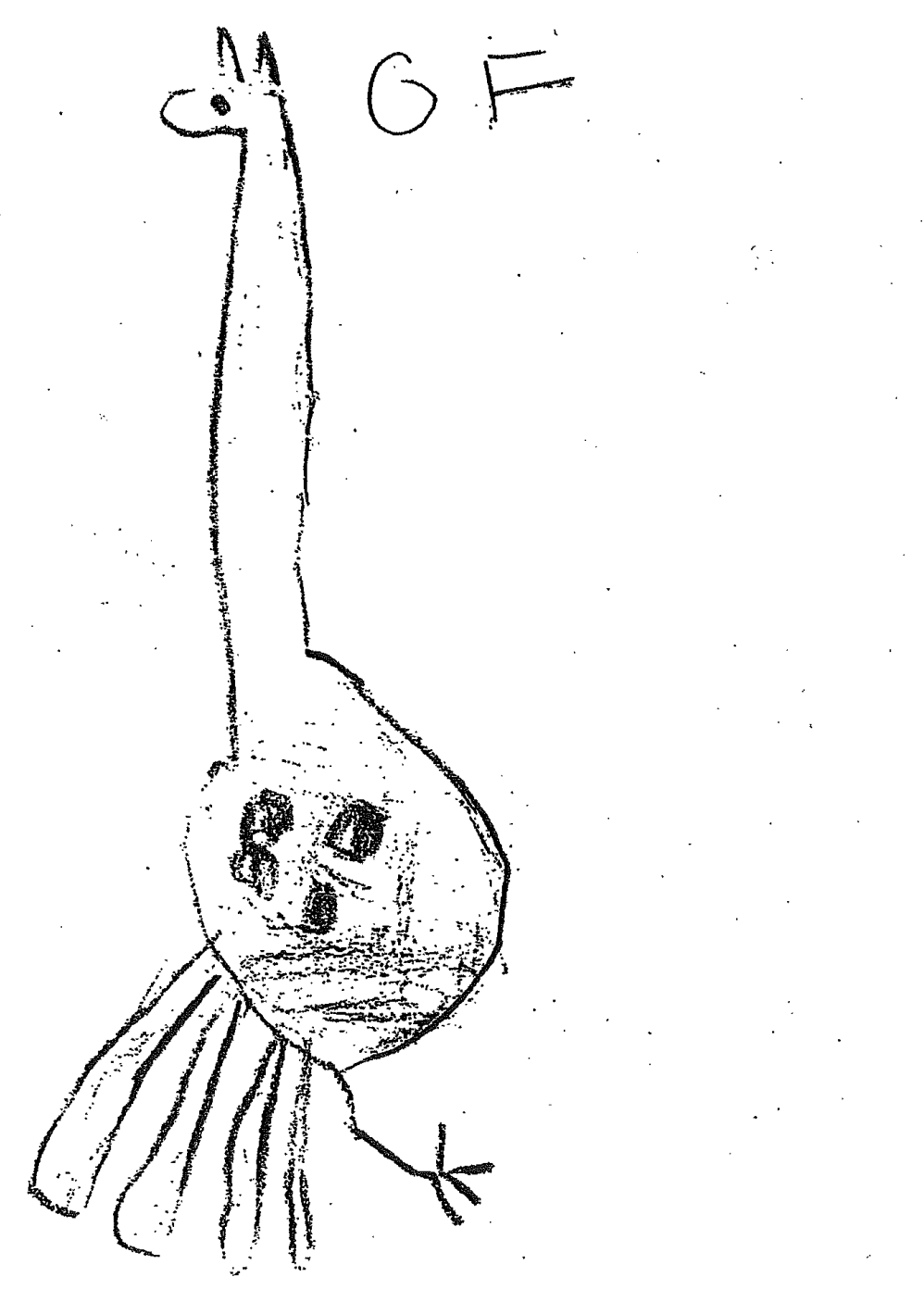

Figure 2. Giraffe

K.W.3 Use a combination of drawing, dictating, and writing to narrate a single event, or several loosely linked events, tell about the events in the order in which they occurred, and provide a reaction to what happened (figure first day of zoo book and last day).

In the following illustration the child (Figure 3) has written to her Dad in a string of invented spelling, with a few conventionally spelled words. Translation of the writing is "Dad you will probably like this book a lot and I am going to the zoo". Considering her dad was deployed oversees this makes sense. The cover of her new book provides a message both to her dad and a portending event of going on a field trip to the zoo. After writing for 8 additional days about what she might see on the final page of the ten page book she writes (Figure 4) "Dad I had a misunderstanding I was too sick to go the zoo and my heart broke". She provides linked events in order in which is logical, tells about what she might see and then provides a powerful reaction to what occurred. Looking at the writing the teacher needs to know what comes next. Knowing this child's writing, the teacher knows the child clearly understands that writing is used for meaning and can express a powerful emotion. In terms of writing development she is moving towards conventional spelling, but might prompt the child to leave spaces between words as she begins her next writing sample. The teacher would also be available to help stretch out the sounds of words such as "probably" used as the child is writing to help her hear more of the consonants. In this example the child is clearly in a stage moving back and forth between phonetic writing and into conventional writing in writing development. In an assessment of writing not only is this a sample used as evidence to support the standard, but also sound/symbol relationship and left to right concepts about print are evident. Providing choice of writing was a powerful incentive to write. 
jel.ccsenet.org

Journal of Education and Learning

Vol. 6, No. 4; 2017

LadY UWvilPry
LEVI BALT.

and IAMGriotovyza

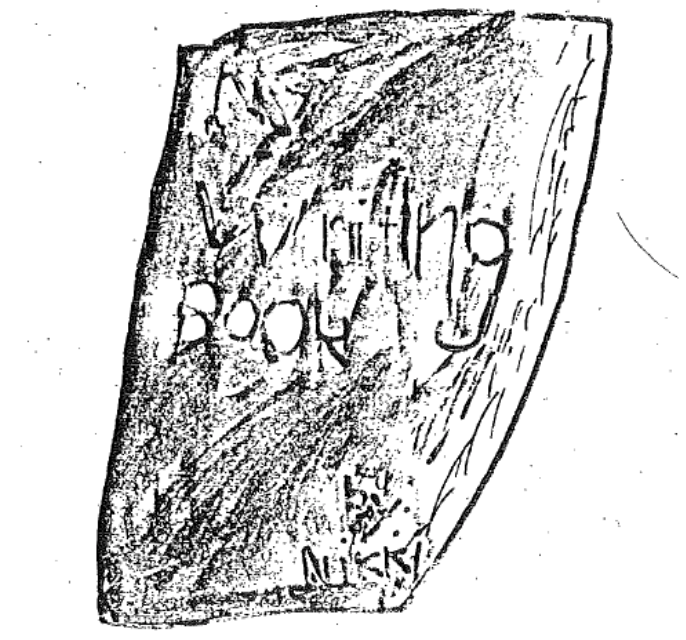

Figure 3. Zoo

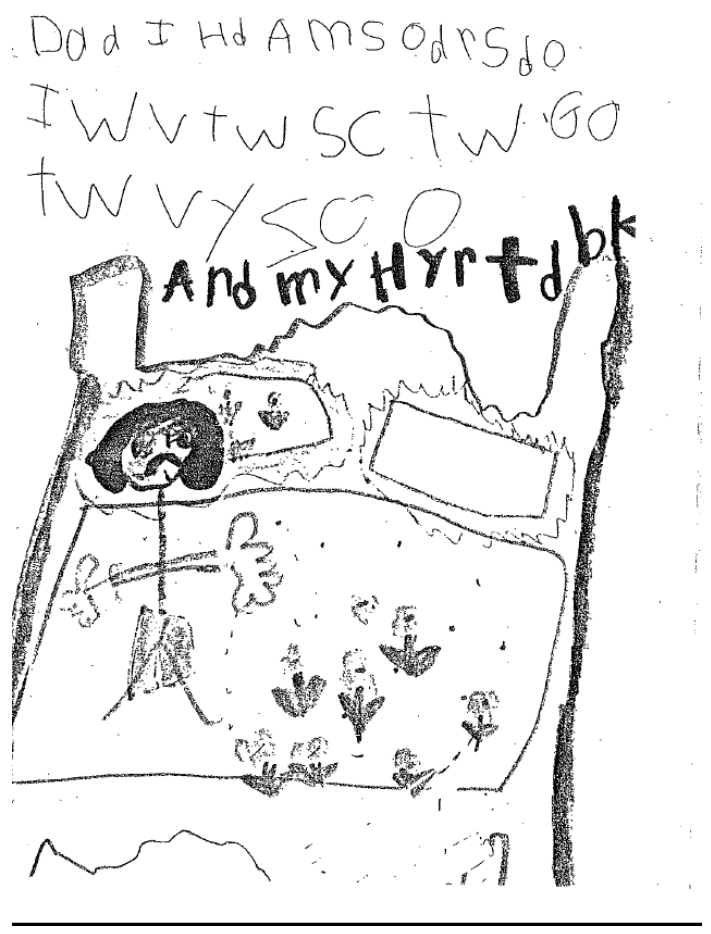

Figure 4. Heart broke

97 
K.W.5 With guidance and support from adults respond to questions and suggestions from peers and add details to strengthen writing as needed.

Dennis has been writing a book about robots and is thinking of a new page "What do the robots do all day?" queries the teacher.

While the written response, "Someday I will build I giant robot" does not directly respond to the question posed metacognitively by the child, the drawing and peer interactions address the standard in helping the child. First the teacher provides support on possible topics and then his peer offer the following verbal prompting.

Shirley: Why did you write "book, book, book" around your robot heart?

Dennis: I didn't, I wrote “bonk, bonk, bonk” like your heart does.

Shirley: But it says "book, book, book".

Dennis: But I wrote "bonk, bonk, bonk—put your hand over your heart, it says bonk, bonk, bonk".

Shirley: (a sigh) It still says, "book, book, book".

Dennis: Looks puzzled and pauses, "oh!"

Although his picture (Figure 5) is prompted by the teacher's initial question, the writing surrounding the picture is developed as the story unfolds. His peer's influence on his writing alerts him to the possibility that his drawing and writing might not match as clearly as he originally thought.

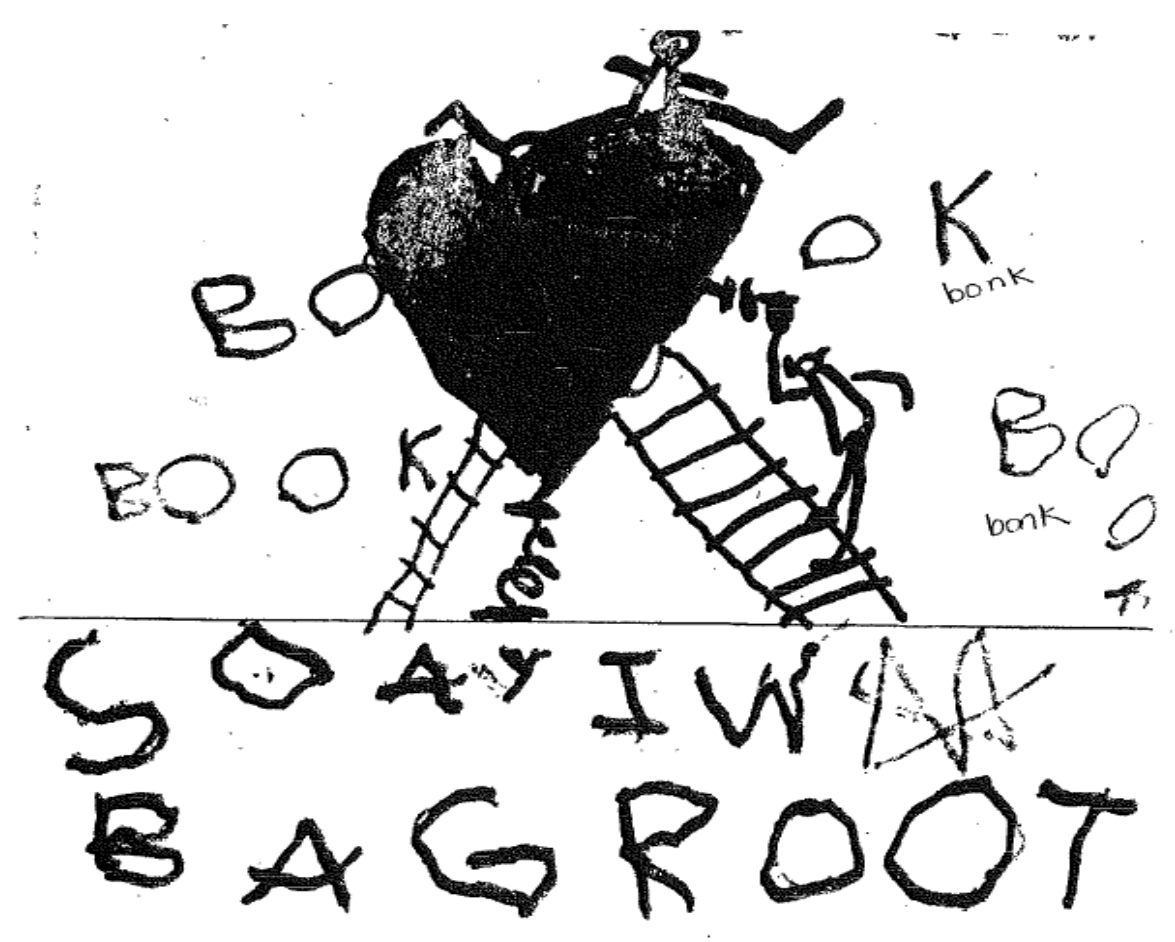

Figure 5. Robots 


\section{Conclusion}

Although somewhat controversial, meeting state or common core standards need not be challenging in the Kindergarten classroom. What is challenging is for the teacher to provide meaningful, developmentally appropriate experiences for students. Table 1 provides the reader with some basic considerations of what teachers need to know about strategies, environmental considerations, assessment opportunities, and differentiated instruction for each standard.

The examples in this article show how engaged students actively construct meaning through writing while meeting standards. These activities show, how, when teachers provide environments where writing is valued and students are viewed as engaged learners... wonderful writing opportunities occur and develop.

\section{References}

Alliance for Childhood. (2010). Citing grave concerns, experts condemn proposed core standards for young children (Press release). Retrieved from http://www.allianceforchildhood.org/sites/allianceforchildhood.org/files/file/standards_press_release2.pdf

Arnold, T. (1997). Parts. New York: Puffin.

Cress, S. (1998). A sense of story: Interactive journal writing in kindergarten. Early Childhood Education Journal, 26(1), 13-17. https://doi.org/10.1023/A:1022926607347

Cress, S. (2004). Assessing students in the "real" kindergarten classroom. Early Childhood Education Journal, 32(2), 95-99. https://doi.org/10.1007/s10643-004-1075-7

Edelman, S. (2013, January 30). Playtime's over kindergartners: Standards stressing kids out. NY Post. Retrieved from http://www.NYPOST.com

Epstein, A. S. (2007). The intentional teacher: Choosing the best strategies for young children's learning. Washington, DC: NAEYC.

Morrow, L. M. (2012). Literacy development in the early years: Helping children read and write. Boston: Pearson.

National Association for the Education of Young Children. (2012). The Common Core State Standards: Caution and Opportunity for Early Childhood Education. Washington, DC: National Association for the Education of Young Children.

National Governors Association Center for Best Practices, Council of Chief State School Officers. (2010). Common core standards. Washington, DC: National Governors Association Center for Best Practices, Council of Chief State School Officers. Retrieved from http://www.corestandards.org/the-standards/

Roskos, K., \& Neuman, S. (2011). The classroom environment. The Reading Teacher, 65, 110-114. https://doi.org/10.1002/TRTR.01021

Snow, K. (2012). Variation in children's experience of kindergarten and the common core. Common Core Issue Brief, 1-16. Retrieved from http://www.naeyc.org/topics/common-core/issue-briefs

Strickland, D. L. (2012). Overcoming the impact of poverty on learning. Reading Today, 29, 25-26.

Sulzby, E., \& Teale, W. (1985). Writing development in early childhood. Educational Horizons, 64, 8-12.

\section{Copyrights}

Copyright for this article is retained by the author(s), with first publication rights granted to the journal.

This is an open-access article distributed under the terms and conditions of the Creative Commons Attribution license (http://creativecommons.org/licenses/by/4.0/). 